\title{
Synthesis and In Vitro AMPK Activation of Cycloalkyl/Alkarylbiguanides with Robust In Vivo Antihyperglycemic Action
}

\author{
Erika Gutierrez-Lara, ${ }^{1,2}$ Carlos Martínez-Conde, ${ }^{1}$ Edgar Rosales-Ortega, ${ }^{1}$ \\ Juan José Ramírez-Espinosa, ${ }^{1}$ Julio C. Rivera-Leyva, ${ }^{1}$ David Centurión, ${ }^{2}$ Karla Carvajal, ${ }^{3}$ \\ Daniel Ortega-Cuellar, ${ }^{3}$ Samuel Estrada-Soto, ${ }^{1}$ and Gabriel Navarrete-Vázquez ${ }^{1}$ \\ ${ }^{1}$ Facultad de Farmacia, Universidad Autónoma del Estado de Morelos, 62209 Cuernavaca, MOR, Mexico \\ ${ }^{2}$ Departamento de Farmacobiología, Cinvestav-Coapa, 14330 Ciudad de México, Mexico \\ ${ }^{3}$ Laboratorio de Nutrición Experimental, Instituto Nacional de Pediatría, 04150 Ciudad de México, Mexico
}

Correspondence should be addressed to Samuel Estrada-Soto; enoch@uaem.mx and Gabriel Navarrete-Vázquez; gabriel_navarrete@uaem.mx

Received 16 August 2017; Accepted 22 October 2017; Published 15 November 2017

Academic Editor: Teodorico C. Ramalho

Copyright (c) 2017 Erika Gutierrez-Lara et al. This is an open access article distributed under the Creative Commons Attribution License, which permits unrestricted use, distribution, and reproduction in any medium, provided the original work is properly cited.

\begin{abstract}
This work describes the design, synthesis in one step, and the in vitro, in vivo, and in silico antidiabetic evaluation of a series of ten alicyclic and aromatic (alkyl +aryl: alkaryl)biguanides, analogues of metformin and phenformin. The design was conceived using isosteric replacement, chain-ring transformation, and lower and higher homologation strategies. All compounds were obtained as crystals and their structure was confirmed on the basis of their spectral data (NMR and mass spectra), and their purity was ascertained by microanalysis. Compounds were in vitro evaluated as activators of AMP-Activated Protein Kinase (AMPK). The results indicated that compounds $\mathbf{4 , 5}$, and $\mathbf{6}$ showed similar or even better effect compared to metformin. Docking analysis was performed with regulatory subunit $\gamma$ of AMPK, showing several interactions with nucleotide binding pocket. The in vivo evaluation of compounds 4-6 at a single dose of $50 \mathrm{mg} / \mathrm{kg}$ was performed in a murine experimental model of diabetes. The results showed an important and robust decrease of plasmatic glucose levels (-40\%). Compound 6 was selected for an oral glucose tolerance test, showing an antihyperglycemic effect similar to metformin. The in vivo results indicated that compounds 4-6 may be effective in treating experimental T2DM.
\end{abstract}

\section{Introduction}

Type 2 diabetes mellitus (T2DM) is a long-lasting and progressive metabolic disease characterized by insulin resistance in several peripheral tissues such as liver, muscle, and adipose, as well as impaired insulin secretion by the pancreas [1]. Metformin (a biguanide, Figure 1) is the most extensively prescribed oral antidiabetic drug for the treatment of T2DM [2]. The main effect of metformin is to decrease hepatic glucose production, being a perfect agent for controlling fasting hyperglycemia. Several mechanisms of action have been proposed, but a previous study [3] reported that metformin increases phosphorylation of the AMP-Activated Protein
Kinase (AMPK), with subsequent activation of AMPK activity in hepatocytes. AMPK is a heterotrimeric protein kinase comprised of three subunits: $\alpha$ catalytic subunit and the regulatory $\beta$ and $\gamma$ subunits [3]. AMPK is activated by phosphorylation of Thr172 residue on the $\alpha$-subunit by kinases LKB1 and CaMKKb. Furthermore, AMP binds to nucleotide binding sites on $\gamma$-subunits to allosterically activate as well as facilitate Thr172 phosphorylation. AMPK plays a role of "fuel gauge" of the cell as it works to guarantee that ATP levels are maintained under situations of energetic stress such as exercise, hypoxia, and starvation [4]. Due to the central role played by AMPK in cellular energy homeostasis, it has emerged as an attractive drug target for the treatment of a 


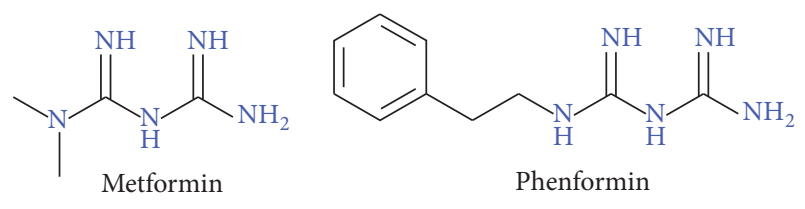

FIGURE 1: Biguanides that activate AMPK.

number of metabolic diseases such as type 2 diabetes mellitus (T2DM) [2].

Another biguanide, phenformin (Figure 1), also activates AMPK, but in 1978 it was retired from the market due to its toxicity, producing lactic acidosis as a major side effect that prompted the withdrawal of phenformin as a treatment for diabetes [5].

In our ongoing research on molecules with antidiabetic activity $[6,7]$, we report in this manuscript the preparation of ten alicyclic and aromatic biguanides (Table 1), as well as the in vitro activation of AMPK. We also describe the molecular docking of the most active compounds in the nucleotide binding site on $\gamma$-subunit of AMPK, and their in vivo antihyperglycemic effect using a streptozotocin-nicotinamide rat model of noninsulin dependent diabetes mellitus.

\section{Materials and Methods}

2.1. Chemicals and Analytical Methods. Starting materials and solvents were purchased from Sigma-Aldrich and were used without any further purification. Melting points were determined using an EZ-Melt MPA120 automated melting point apparatus from Stanford Research Systems and are uncorrected. Reactions were monitored by thin layer chromatography on $0.2 \mathrm{~mm}$ precoated silica gel $60 \mathrm{~F}_{254}$ Merck plates. ${ }^{1} \mathrm{H}$ NMR spectra were recorded on Varian Oxford $(400 \mathrm{MHz})$ and ${ }^{13} \mathrm{C} \mathrm{NMR}(100 \mathrm{MHz})$, as well as ${ }^{1} \mathrm{H} \mathrm{NMR}$ $(200 \mathrm{MHz})$ and ${ }^{13} \mathrm{C}$ NMR $(50 \mathrm{MHz})$ instruments. Chemical shifts are given in ppm relative to tetramethylsilane $\left(\mathrm{Me}_{4} \mathrm{Si}\right.$, $\delta=0$ ) in $\mathrm{DMSO}-\mathrm{d}_{6}$ and $\mathrm{CDCl}_{3} ; J$ values are given in $\mathrm{Hz}$. The following abbreviations are used: s, singlet; d, doublet; q, quartet; dd, doublet of doublet; $t$, triplet; $m$, multiplet; bs, broad signal. MS were recorded on a JEOL JMS-700 spectrometer by electronic impact. Element analyses have been carried out on an Elementar Vario ELIII instrument.

2.2. General Procedure for the Synthesis of Compounds 1-10. To a solution of dicyandiamide $21(0.5 \mathrm{~g}, 0.0060 \mathrm{~mol})$ in toluene $(5 \mathrm{~mL})$ was added $1.1 \mathrm{~mol}$ equiv of corresponding alkylamines 11-15 or arylamines 16-20. After the reaction mixture was stirred at room temperature for $15 \mathrm{~min}$, a mixture $50: 50$ of $\mathrm{HCl}$ diluted in water $(2.5 \mathrm{~mL})$ was added dropwise. This mixture was stirred at reflux for 3 to $16 \mathrm{~h}$. After that, the obtained residue was neutralized with a diluted solution of $\mathrm{NH}_{4} \mathrm{OH}$. Solvent was removed under vacuum, and the residues were washed with water. The crude solid products were then recrystallized from ethanol affording title compounds (Figure 2, Table 1).
2.2.1. N,N-Diethylimidodicarbonimidic Diamide (1). Yield $37 \%$. White crystals obtained from ethanol. Mp $190^{\circ} \mathrm{C}(\mathrm{Dec})$. ${ }^{1} \mathrm{H}$ NMR $\left(400 \mathrm{MHz}, \mathrm{DMSO}-d_{6}\right) \delta: 1.16\left(\mathrm{t}, 6 \mathrm{H}, \mathrm{CH}_{3} \times 2\right)$, $2.89\left(\mathrm{q}, 4 \mathrm{H}, \mathrm{N}-\mathrm{CH}_{2} \times 2\right), 6.60(\mathrm{bs}, 5 \mathrm{H},-\mathrm{NH} \times 5) \mathrm{ppm} .{ }^{13} \mathrm{C}$ NMR (100 MHz, DMSO-d6) $\delta$ : $11.1\left(-\mathrm{CH}_{3}\right), 41.4\left(\mathrm{CH}_{2}\right), 162.9$ (C=NH) ppm. MS/EI: $m / z$ (\% int. rel). $157\left(\mathrm{M}^{+}, 25 \%\right), 85$ (100\%). Anal. Calcd for $\mathrm{C}_{6} \mathrm{H}_{15} \mathrm{~N}_{5}$ : C, 45.84; H, 9.62; N, 44.55. Found: C, 45.80; H, 9.58; N, 44.57.

2.2.2. N-[Amino(imino)methyl]pyrrolidine-1-carboximidamide (2). Yield $46 \%$. White crystals obtained from ethanol. Mp 156.4-158. ${ }^{\circ}$ C. ${ }^{1} \mathrm{H}$ NMR (400 MHz, DMSO- $d_{6}$ ) $\delta: 1.82$ (q, $4 \mathrm{H}$, $\left.\mathrm{CH}_{2}-\mathrm{CH}_{2}\right), 3.07$ (t, 4H, N-CH $\times$ 2), $6.60(\mathrm{bs}, 5 \mathrm{H},-\mathrm{NH} \times 5)$ ppm. ${ }^{13} \mathrm{C}$ NMR (100 MHz, DMSO-d6) $\delta: 23.7\left(\mathrm{CH}_{2}-\mathrm{CH}_{2}\right)$, $44.7\left(\mathrm{CH}_{2}-\mathrm{N}\right), 162.9$ (C=NH) ppm. MS/EI: $m / z$ (\% int. rel). $155\left(\mathrm{M}^{+}, 2 \%\right), 85$ (100\%). Anal. Calcd for $\mathrm{C}_{6} \mathrm{H}_{13} \mathrm{~N}_{5}$ : C, 46.43; H, 8.44; N, 45.12. Found: C, 46.50; H, 8.48; N, 45.01.

2.2.3. N-[Amino(imino)methyl]piperidine-1-carboximidamide (3). Yield $63 \%$. White crystals obtained from ethanol. Mp 116.5-118.0 ${ }^{\circ}$. ${ }^{1} \mathrm{H}$ NMR (400 MHz, DMSO- $\left.d_{6}\right) \delta: 1.03(\mathrm{~m}, 4 \mathrm{H}$, $\left.\mathrm{CH}_{2}-\mathrm{CH}_{2}\right), 1.05\left(\mathrm{~m}, 2 \mathrm{H}, \mathrm{CH}_{2}\right) 3.40\left(\mathrm{t}, 4 \mathrm{H}, \mathrm{N}-\mathrm{CH}_{2} \times 2\right), 6.58$ (bs, $5 \mathrm{H},-\mathrm{NH} \times 5) \mathrm{ppm} .{ }^{13} \mathrm{C}$ NMR $(100 \mathrm{MHz}, \mathrm{DMSO}-d 6) \delta$ : $18.5\left(\mathrm{CH}_{2}-\mathrm{CH}_{2}\right), 30.6\left(\mathrm{CH}_{2}\right), 56.1\left(\mathrm{CH}_{2}-\mathrm{N}\right), 162.9(\mathrm{C}=\mathrm{NH})$ ppm. MS/EI: $m / z$ (\% int. rel). $169\left(\mathrm{M}^{+}, 40 \%\right), 85$ (100\%). Anal. Calcd for $\mathrm{C}_{7} \mathrm{H}_{15} \mathrm{~N}_{5}$ : C, 49.68; H, 8.93; N, 41.38. Found: C, 49.62; H, 8.90; N, 41.40.

2.2.4. N-[Amino(imino)methyl]morpholine-4-carboximidamide (4). Yield 22\%. White crystals obtained from ethanol. Mp 178.4-180.5 C. ${ }^{1} \mathrm{H}$ NMR (400 MHz, DMSO-d6) $\delta: 3.06$ (t, $4 \mathrm{H}$, $\mathrm{CH}_{2}-\mathrm{O}-\mathrm{CH}_{2}$ ), 3.75 (t, $\left.4 \mathrm{H}, \mathrm{N}-\mathrm{CH}_{2} \times 2\right), 6.61$ (bs, $5 \mathrm{H}, \mathrm{NH} \times$ 5) ppm. ${ }^{13} \mathrm{C}$ NMR $(100 \mathrm{MHz}, \mathrm{DMSO}-d 6) \delta: 43.2\left(\mathrm{CH}_{2}-\mathrm{N}\right)$, $63.7\left(\mathrm{CH}_{2}-\mathrm{O}\right), 162.3(\mathrm{C}=\mathrm{NH})$ ppm. MS/EI: $m / z$ (\% int. rel). 171 $\left(\mathrm{M}^{+}, 15 \%\right), 85$ (100\%). Anal. Calcd for $\mathrm{C}_{6} \mathrm{H}_{13} \mathrm{~N}_{5} \mathrm{O}$ : C, 42.09; $\mathrm{H}, 7.68 ; \mathrm{N}, 40.91$. Found: C, 42.10; H, 7.65; N, 40.88 .

2.2.5. N-[Amino(imino)methyl]-4-methylpiperazine-1-carboximidamide (5). Yield 54\%. White crystals obtained from ethanol. Mp $148^{\circ} \mathrm{C}$ (Dec). ${ }^{1} \mathrm{H}$ NMR (400 MHz, DMSO- $d_{6}$ ) $\delta: 2.48\left(\mathrm{~s}, 3 \mathrm{H}, \mathrm{CH}_{3}\right), 2.73\left(\mathrm{~m}, 4 \mathrm{H}, \mathrm{CH}_{2}-\mathrm{N}-\mathrm{CH}_{2}\right), 3.38(\mathrm{~m}$, $\left.4 \mathrm{H}, \mathrm{CH}_{2}-\mathrm{NMe}-\mathrm{CH}_{2}\right), 6.71$ (bs, $\left.5 \mathrm{H}, \mathrm{NH} \times 5\right) \mathrm{ppm} .{ }^{13} \mathrm{C} \mathrm{NMR}$ $(100 \mathrm{MHz}, \mathrm{DMSO}-d 6) \delta$ : $42.5\left(\mathrm{CH}_{2}-\mathrm{N}\right), 43.3\left(\mathrm{CH}_{2}-\mathrm{N}\right), 49.6$ $\left(\mathrm{CH}_{3}\right), 163.3(\mathrm{C}=\mathrm{NH})$ ppm. MS/EI: $m / z$ (\% int. rel). $184\left(\mathrm{M}^{+}\right.$, $2 \%), 85$ (100\%). Anal. Calcd for $\mathrm{C}_{7} \mathrm{H}_{16} \mathrm{~N}_{6}$ : C, 45.63; H, 8.75; N, 45.61. Found: C, 45.70; H, 8.75; N, 45.58.

2.2.6. N-Benzylimidodicarbonimidic Diamide (6). Yield 56\%. White crystals obtained from ethanol. Mp $184.2-186.8^{\circ} \mathrm{C} .{ }^{1} \mathrm{H}$ NMR (400 MHz, DMSO- $\left.d_{6}\right) \delta: 3.99\left(\mathrm{~d}, 2 \mathrm{H}, \mathrm{CH}_{2}\right), 7.30(\mathrm{~m}$, 2H, H-2, H-6), 7.39 (m, 2H, H-3, H-5), 7.50 (m, 1H, H-4), 8.60 $(\mathrm{bs}, 6 \mathrm{H}, \mathrm{NH} \times 6) \mathrm{ppm} .{ }^{13} \mathrm{C} \mathrm{NMR}(100 \mathrm{MHz}, \mathrm{DMSO}-d 6) \delta$ : $42.6\left(\mathrm{CH}_{2}-\mathrm{N}\right), 129.4$ (C-4), 128.8 (C-2, C-6), 129.0 (C-3, C-5), 134.5 (C-1), 154.9 (C=NH), $156.1(\mathrm{C}=\mathrm{NH}) \mathrm{ppm}$. MS/EI: $\mathrm{m} / z$ (\% int. rel). $191\left(\mathrm{M}^{+}, 2 \%\right), 91(100 \%), 85$ (40\%). Anal. Calcd for $\mathrm{C}_{9} \mathrm{H}_{13} \mathrm{~N}_{5}$ : C, 56.53; H, 6.85; N, 36.62. Found: C, 56.50; H, $6.85 ; \mathrm{N}, 36.61$. 


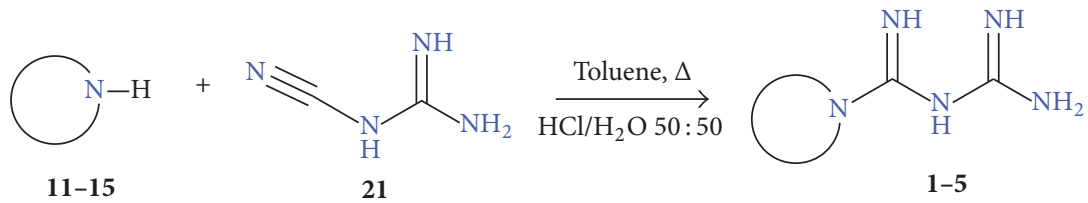<smiles>[R]c1ccc(CN)cc1</smiles>

16-20<smiles>N#CNC(=N)N</smiles>

FIGURE 2: Scheme reaction to obtain compounds 1-10.<smiles>[R]c1ccc(CNC(=N)NC(=N)N)cc1</smiles>

TABLE 1: Physicochemical properties of biguanides 1-10.

\begin{tabular}{|c|c|c|c|c|c|c|c|}
\hline Compd. & $\mathrm{R}$ & Yield (\%) & $\mathrm{Mp}\left({ }^{\circ} \mathrm{C}\right)$ & $\begin{array}{l}\text { Mol. Weight } \\
(\mathrm{g} / \mathrm{mol})\end{array}$ & Reaction time (h) & & \\
\hline 1 & Diethylamine & 37 & $190(\mathrm{dec})$ & 157 & 5 & & \\
\hline 2 & Pyrrolidine & 46 & $116.5-119$ & 155 & 5 & & \\
\hline 3 & Piperidine & 63 & $156.4-158.7$ & 169 & 5 & & \\
\hline 4 & Morpholine & 22 & $178.4-180.5$ & 171 & 7 & $\mathrm{NH}$ & $\mathrm{NH}$ \\
\hline 5 & 4-Methylpiperazine & 54 & $148(\mathrm{dec})$ & 184 & 7 & & \\
\hline 6 & Benzylamine & 56 & $184.2-186.8$ & 191 & 7 & & \\
\hline 7 & Aniline & 75 & $185.3-187.4$ & 177 & 7 & & \\
\hline 8 & 4-Nitroaniline & 68 & $145.5-148.7$ & 222 & 16 & & \\
\hline 9 & 4-Chloroaniline & 80 & $161.9-163.3$ & 211 & 10 & & \\
\hline 10 & 4-Fluoroaniline & 85 & $207.5-209.2$ & 195 & 4 & & \\
\hline
\end{tabular}

2.2.7. N-Phenylimidodicarbonimidic Diamide (7). Yield 75\%. White crystals obtained from ethanol. Mp 185.3-187.4 ${ }^{\circ} \mathrm{C} .{ }^{1} \mathrm{H}$ NMR (400 MHz, DMSO- $\left.d_{6}\right) \delta: 7.19$ (m, 5H, H-2 to H-6), 9.91 (bs, $6 \mathrm{H}, \mathrm{NH} \times 6) \mathrm{ppm} .{ }^{13} \mathrm{C}$ NMR $(100 \mathrm{MHz}, \mathrm{DMSO}-d 6) \delta$ : 121.4 (C-4), 123.7 (C-2, C-6), 129.1 (C-3, C-5), 139.1 (C-1), 155.7 $(\mathrm{C}=\mathrm{NH}), 161.6(\mathrm{C}=\mathrm{NH})$ ppm. MS/EI: $m / z$ (\% int. rel). 177 $\left(\mathrm{M}^{+}, 70 \%\right), 119$ (100\%), 85 (20\%). Anal. Calcd for $\mathrm{C}_{8} \mathrm{H}_{11} \mathrm{~N}_{5}$ : C, 54.22; H, 6.26; N, 39.52. Found: C, 54.20; H, 6.21; N, 39.60.

2.2.8. N-(4-Nitrophenyl)imidodicarbonimidic Diamide (8). Yield $68 \%$. White crystals obtained from ethanol. Mp 145.5-148.7 ${ }^{\circ}$ C. ${ }^{1} \mathrm{H}$ NMR (400 MHz, DMSO- $\left.d_{6}\right) \delta: 7.68$ (d, 2H, $\mathrm{H}-2, \mathrm{H}-6, J o=9.2 \mathrm{~Hz}), 8.21(\mathrm{~d}, 2 \mathrm{H}, \mathrm{H}-3, \mathrm{H}-5, \mathrm{Jo}=9.2 \mathrm{~Hz}$ ), 11.07 (bs, 6H, NH $\times 6)$ ppm. ${ }^{13} \mathrm{C}$ NMR $(100 \mathrm{MHz}$, DMSOd6) $\delta: 119.4$ (C-2, C-6), 125.5 (C-3, C-5), 142.9 (C-1), 144.5 (C4), $151.6(\mathrm{C}=\mathrm{NH}), 155.4(\mathrm{C}=\mathrm{NH}) \mathrm{ppm}$. MS/EI: $m / z$ (\% int. rel). $222\left(\mathrm{M}^{+}, 70 \%\right), 165(100 \%), 85$ (5\%). Anal. Calcd for $\mathrm{C}_{8} \mathrm{H}_{10} \mathrm{~N}_{6} \mathrm{O}_{2}$ : C, 43.24; $\mathrm{H}, 4.54 ; \mathrm{N}, 37.82$. Found: C, 43.31; $\mathrm{H}$, $4.50 ; \mathrm{N}, 37.79$.

2.2.9. N-(4-Chlorophenyl)imidodicarbonimidic Diamide (9). Yield $80 \%$. White crystals obtained from ethanol. $\mathrm{Mp}$ 161.9-163.3 ${ }^{\circ}$. ${ }^{1} \mathrm{H}$ NMR (200 MHz, DMSO- $\left.d_{6}\right) \delta: 7.30$ (d, 2H,
$\mathrm{H}-2, \mathrm{H}-6, J o=8.4 \mathrm{~Hz}), 7.39(\mathrm{~d}, 2 \mathrm{H}, \mathrm{H}-3, \mathrm{H}-5, J o=8.8 \mathrm{~Hz})$, 9.99 (bs, 6H, NH $\times 6$ ) ppm. ${ }^{13} \mathrm{C}$ NMR $(50 \mathrm{MHz}, \mathrm{DMSO}-d 6)$ $\delta: 122.5$ (C-2, C-6), 127.27 (C-3, C-5), 128.9 (C-4), 136.3 (C-1), $155.3(\mathrm{C}=\mathrm{NH}), 161.8(\mathrm{C}=\mathrm{NH})$ ppm. MS/EI: $m / z$ (\% int. rel). 211 $\left(\mathrm{M}^{+}\right.$, 90\%), $154(100 \%), 85$ (10\%). Anal. Calcd for $\mathrm{C}_{8} \mathrm{H}_{10} \mathrm{~N}_{5} \mathrm{Cl}$ : C, 45.40; H, 4.76; N, 33.09. Found: C, 45.38; H, 4.78; N, 33.12.

2.2.10. N-(4-Fluorophenyl)imidodicarbonimidic Diamide (10). Yield $85 \%$. White crystals obtained from ethanol. Mp 207.5-209.2 ${ }^{\circ}$. ${ }^{1} \mathrm{H}$ NMR (200 MHz, DMSO-d 6 ) $\delta: 7.18$ (m, $2 \mathrm{H}, \mathrm{H}-3, \mathrm{H}-5, \mathrm{Jo}=9.2 \mathrm{~Hz}), 7.42(\mathrm{~m}, 2 \mathrm{H}, \mathrm{H}-2, \mathrm{H}-6, \mathrm{Jo}=$ $9.2 \mathrm{~Hz}), 9.91(\mathrm{bs}, 6 \mathrm{H}, \mathrm{NH} \times 6) \mathrm{ppm} .{ }^{13} \mathrm{C} \mathrm{NMR}(50 \mathrm{MHz}$, DMSO-d6) $\delta: 117.8\left(\mathrm{~d}, \mathrm{C}-3, \mathrm{C}-5,{ }^{2} J_{\mathrm{C}-F}=11.25 \mathrm{~Hz}\right), 125.6(\mathrm{~d}$, $\left.\mathrm{C}-2, \mathrm{C}-6,{ }^{3} J_{\mathrm{C}-\mathrm{F}}=3.9 \mathrm{~Hz}\right), 137.6\left(\mathrm{~d}, \mathrm{C}-1,{ }^{4} J_{\mathrm{C}-\mathrm{F}}=1.55 \mathrm{~Hz}\right), 160.9$ $\left(\mathrm{d}, \mathrm{C}-4,{ }^{1} J_{\mathrm{C}-\mathrm{F}}=294.7 \mathrm{~Hz}\right), 159.8(\mathrm{C}=\mathrm{NH}), 162.1(\mathrm{C}=\mathrm{NH}) \mathrm{ppm}$. MS/EI: $m / z$ (\% int. rel). $195\left(\mathrm{M}^{+}, 80 \%\right), 111$ (100\%), 85 (70\%). Anal. Calcd for $\mathrm{C}_{8} \mathrm{H}_{10} \mathrm{~N}_{5} \mathrm{~F}$ : C, 49.22; H, 5.16; N, 35.88. Found: C, 49.21; H, 5.20; N, 35.90.

\subsection{Biological Activity}

2.3.1. In Vitro AMPK Activation. Primary rat hepatocytes were obtained by collagenase digestion as described by Berry 
and Friend [8]. Fresh isolated hepatocytes were equally distributed in collagen-coated dishes and incubated at $37^{\circ} \mathrm{C}$ for $2 \mathrm{~h}$ in medium $\alpha$ MEM (Gibco; cat 11900-024), $10 \%$ FBS, $100 \mathrm{U} / \mathrm{mL}$ penicillin, and $100 \mu \mathrm{g} / \mathrm{mL}$ streptomycin. The cultured dishes were then washed three times with PBS to remove unattached dead cells. Dishes were randomly assigned to receive fresh FBS-free medium without or with different concentrations of both metformin $(10 \mathrm{mM})$ and ten of its analogues ( 1 and $10 \mathrm{mM}$ ) for $1 \mathrm{~h}$. After this time, the plated cells were washed three times with cold PBS. The cells were then lysed using a buffer containing $50 \mathrm{mM}$ HEPES (pH 7.5), $50 \mathrm{mM} \mathrm{KCl}, 1 \mathrm{mM}$ EDTA, 5 mM EGTA, $1 \mathrm{mM}$ glycerolphosphate, $0.1 \%$ (vol/vol) Triton X-100, $50 \mathrm{mM} \mathrm{NaPPi}$, $1 \mathrm{nM}$ orthovanadate, and $1 \mathrm{nM}$ DTT, a standard complete protease inhibitor mixture (Roche). The lysates were then centrifuged $\left(10,000 \mathrm{~g}, 10 \mathrm{~min}, 4^{\circ} \mathrm{C}\right)$, and the supernatants were stored at $-80^{\circ} \mathrm{C}$. The activation of AMPK and its target protein, acetyl-CoA carboxylase (ACC), was determined by immunoblot detection with antibodies against phospho$\mathrm{Thr}^{172}$ AMPK and phospho-Ser ${ }^{79}$ ACC1, as well as total AMPK, ACC, and actin as loading controls. All antibodies were purchased from Cell Signaling.

2.3.2. In Vivo Antidiabetic Activity. Male Wistar rats weighing an average of $300 \mathrm{~g}$ were used. They were maintained at $25^{\circ} \mathrm{C}$ in a $12 \mathrm{~h}$ a light/dark cycle and at $45-65 \%$ of humidity during experimentation time. All animal procedures were developed in accordance with the Mexican Federal Regulations for Animal Experimentation and Care, ratified by the Institutional Animal Care and Use Committee (UNAM) based on US National Institute of Health Publication \#85-23 $[9,10]$.

2.3.3. Induction of Diabetes. Streptozotocin (STZ) was dissolved in citrate buffer ( $\mathrm{pH} 4.5)$ and nicotinamide was dissolved in normal physiological saline solution. Non-insulindependent diabetes rat model was induced in overnight fasted

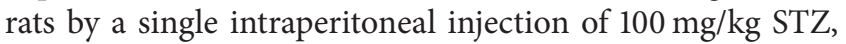
$15 \mathrm{~min}$ before the i.p. administration of $40 \mathrm{mg} / \mathrm{kg}$ of nicotinamide. Hyperglycemia was confirmed by elevated glucose concentration in plasma, determined after 2 weeks by stripglucometer. The animals with blood glucose concentration higher than $200 \mathrm{mg} / \mathrm{dL}$ were used for the antidiabetic study $[11,12]$.

2.3.4. Non-Insulin-Dependent Diabetes Mellitus Rat Model. The diabetic animals were divided into three groups of five animals each $(n=5)$. Rats of experimental groups were given a solution of compounds $4-6(50 \mathrm{mg} / \mathrm{kg}$ body weight, prepared in tween $80,10 \%)$. Control group animals were also treated with saline plus tween $80,10 \%$. Metformin $(50 \mathrm{mg} / \mathrm{kg}$ ) was used as antihyperglycemic reference drug. Blood samples were collected from the caudal vein at $0,1,3,5$, and $7 \mathrm{~h}$ after vehicle, compound, and drug administration. Blood glucose concentration was estimated by enzymatic glucose oxidase method using a commercial glucometer [13]. The percentage variation of glycemia for each group was calculated in relation to initial $(0 \mathrm{~h})$ level, according to

$$
\% \text { variation of glycemia }=\left(\frac{\text { Glu } x-\text { Glu } 0}{\text { Glu } 0}\right) \times 100,
$$

where Glu0 were initial glycemia values and Glux were the glycemia values at $1,3,5$, and $7 \mathrm{~h}$, respectively. All values were expressed as mean \pm SEM. Statistical significance was estimated by analysis of variance (ANOVA); $p<0.05$ implies significance.

2.3.5. Glucose Tolerance Test. Normoglycemic rats were divided into groups of five animals each $(n=5)$. Thirty min after administration of test compounds, a dose of $2 \mathrm{~g} / \mathrm{kg}$ of glucose solution was orally administered to each animal. Compound 6 (50 mg/kg), metformin $(50 \mathrm{mg} / \mathrm{kg})$, and vehicle (tween 80,10\%) were administered to rats in the same volume of solution. Blood samples were collected from the tail tip at 0 (before oral administration), 1, 1.5, 2, 2.5, and $3 \mathrm{~h}$ after vehicle, positive control, or test compound administration.

2.4. Docking Studies. Discovery Studio version 3.5 and Pymol version 1.0 were used for visualization. The crystal structure of AMPK was retrieved from the PDB with the accession code: 2UV4. Docking calculations were conducted with AutoDock Vina. The program performs several runs in each docking experiment. Each run provides one predicted binding mode. All water molecules and also cocrystal ligand $\left(5^{\prime}\right.$-adenylic acid) were removed from the crystallographic structure. The AutoDock Vina plugin through Pymol program was used, where we generated the grid maps. Each grid was centered at the crystallographic coordinates of the cocrystal ligand. The grid dimensions were $20 \times 20 \times 20 \AA^{3}$ with points separated by $1.0 \AA$. Also, the protein file was selected as the rigid part, and the ligand file as the flexible one, allowing all its torsions to rotate during docking. AutoDock Vina uses default algorithms of searching and automatically prepares the files for use as it adds charges and polar hydrogens to the protein necessary to perform scoring calculations; it clusters showing only the main results. The number of docking runs was 10 . After finishing, the poses were visualized on Pymol and compared against the cocrystalized ligand over the protein.

2.4.1. Docking Validation. The molecular docking protocol was validated by redocking of cocrystal ligand $\left(5^{\prime}\right.$-adenylic acid) into the active site of the structure of AMPK. The root mean square deviation between the cocrystal ligand and the docked structure was less than $2.5 \AA$. This value indicates that the parameters for docking simulations are good in reproducing orientation and conformation in the Xray crystal structure of enzyme and receptors.

\section{Results and Discussion}

3.1. Chemistry. Compounds $\mathbf{1}-\mathbf{1 0}$ were designed on the basis of the structure of metformin and phenformin (Figure 1, 
Table 1), maintaining the biguanide group, removing both dimethyl and phenylethyl side chains, and substituting the proximal amino group with diethyl or cycloalkyl groups using a straightforward approach called chain-ring transformation, attaining conformational constraint connecting alkyl substituents to give the corresponding cyclic analogues. The homologation criteria were employed to pass from pyrrolidine to piperidine. A homologous series is a group of compounds that differ by a constant unit, generally a methylene group [14]. Morpholine and 4-methylpiperazine derivatives were selected as isosteric replacements of piperidine. Benzyl or 4-substituted phenyl groups were designed as lower homologues, with one or two methylene groups less than those presented by phenformin. Some physicochemical properties of compounds 1-10 are described in Table 1.

Compounds 1-10 were prepared in a single step starting from cyanoguanidine (21), which was condensed with several alkylamines 11-15 or aryl amines 16-20 under reflux conditions (Figure 2). Title compounds were recovered with $22-85 \%$ yields and purified by recrystallization with ethanol. Their chemical structures were confirmed by spectral data (NMR and mass spectra), and their purity was ascertained by elemental analysis.

3.2. In Vitro Biological Activity. To test the ability of each derivative to activate AMPK, an in vitro assay was performed on a primary culture of hepatocytes. Aliquots of stock solutions of the analogues (dissolved in DMSO) were diluted with the assay buffer, using metformin as positive control. The phosphorylation of AMPK and its target ACC were assessed by immunoblot analysis, where it is observed that aliphatic or alicyclic compounds 1-3 were not able to activate the enzyme (data not shown). Conversely, we found that AMPK phosphorylation (activation) was increased in a concentrationdependent manner with compounds 4,5 , and 6 , being more pronounced with compound $\mathbf{6}$; in fact, the concentrations of three of the compounds required for activation of AMPK were significantly lower than those of metformin (Figure 3). On the other hand, aromatic biguanides 7-10 were unable to activate the AMPK. These results are in accordance with those reported in a parallel work performed with closely related biguanides [15].

In the immunoblot not only is the phosphorylated AMPK observed, but also the phosphorylated ACC (acetyl-CoA carboxylase) in serine 79 can be detected. This enzyme is one of the targets of AMPK. The phosphorylation of this enzyme causes its inactivation, and this leads to an increase in the oxidation of free fatty acids [16]. The phosphorylation of ACC indicates that analogues induce the phosphorylation (activation) of AMPK, which leads to modification of the different metabolic pathways.

\subsection{In Silico Studies}

3.3.1. Docking Analysis. Based on the in vitro biological assay of AMPK activation, the most active compounds were selected to explain the experimental activities. On this basis, a preliminary molecular docking study was conducted to evaluate the putative binding mode of compounds 4-6
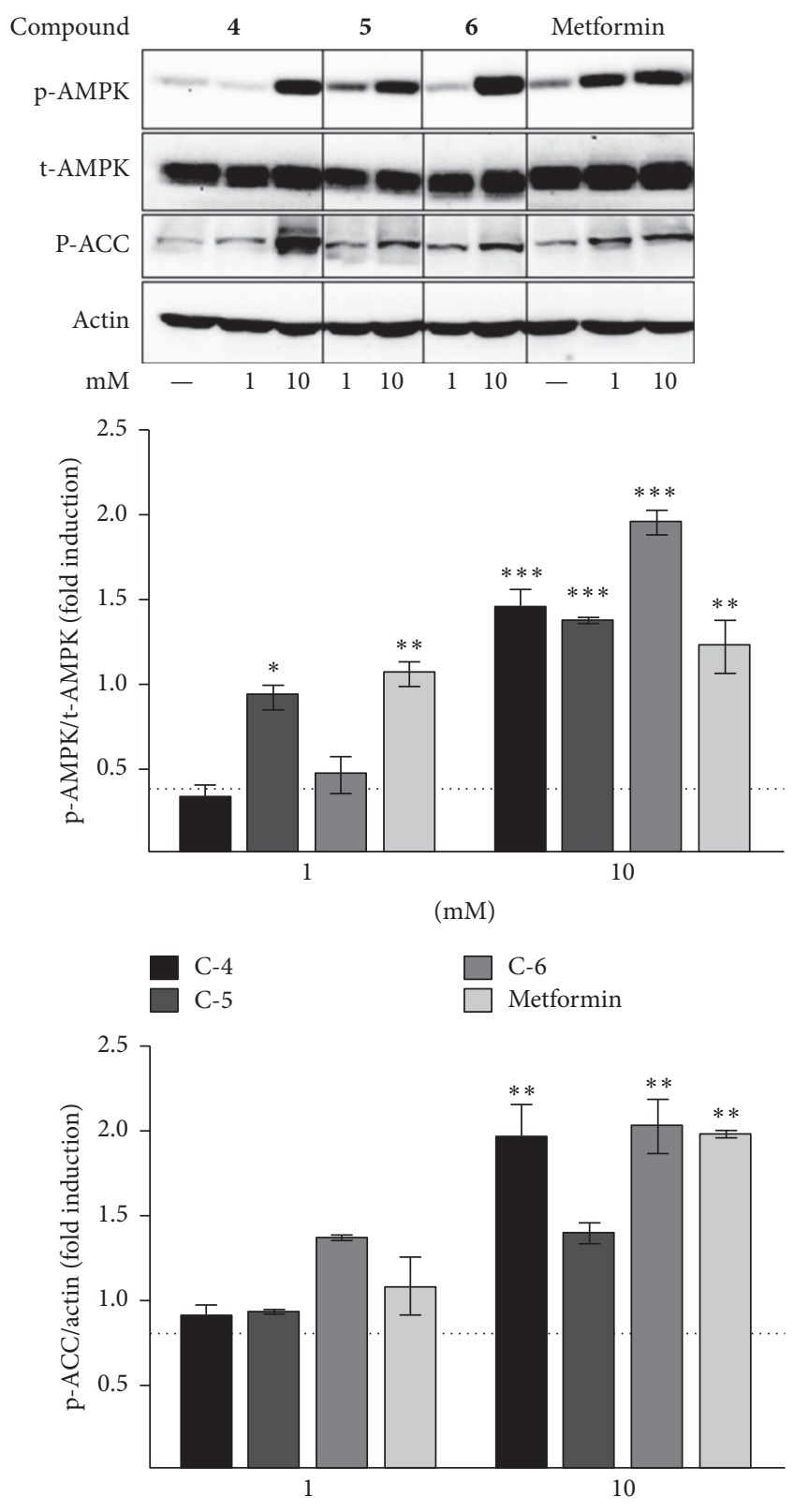

$(\mathrm{mM})$

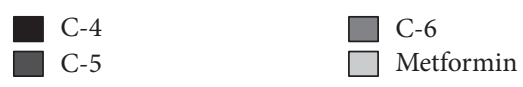

FIGURE 3: AMPK phosphorylation by compounds 4-6. The analogues $\mathbf{4}$ and $\mathbf{5}$ are able to activate the enzyme in a similar way to metformin, whereas the analogue $\mathbf{6}$ appears to induce AMPK phosphorylation in a larger extent. ${ }^{*} p<0.05,{ }^{* *} p<0.01$, and ${ }^{* * *} p<0.001$.

into the regulatory $\gamma$-subunit of AMPK. This molecular docking reveals that compounds $\mathbf{4}$ and $\mathbf{5}$ internalize into the nucleotide binding pocket of AMPK and interact by electrostatic and hydrogen bonds with Asp-317 and Thr200, and both residues are essential for the activation of this enzyme ( $\Delta G=5.2 \mathrm{kcal} / \mathrm{mol}$ for both compounds). However, compound 6 (the most active in vitro) showed an 
TABLE 2: Toxicity profiles predicted for compounds $\mathbf{4 - 6}$, metformin, and phenformin.

\begin{tabular}{|c|c|c|c|c|c|c|c|c|}
\hline \multirow{3}{*}{ Compd. } & \multicolumn{4}{|c|}{$\mathrm{LD}_{50}(\mathrm{mg} / \mathrm{kg})$} & \multicolumn{4}{|c|}{$\begin{array}{l}\text { Probability of inhibition } \\
\quad\left(\mathrm{IC}_{50} \text { or } K i<10 \mu \mathrm{M}\right)\end{array}$} \\
\hline & \multicolumn{2}{|c|}{ Mouse } & \multicolumn{2}{|c|}{ Rat } & \multicolumn{3}{|c|}{ CYP450 isoform } & \multirow{2}{*}{ hERG } \\
\hline & i.p. & p.o. & i.p. & p.o. & $3 \mathrm{~A} 4$ & 2D6 & $1 \mathrm{~A} 2$ & \\
\hline 4 & 400 & 510 & 260 & 850 & 0.01 & 0.06 & 0.01 & 0.02 \\
\hline 5 & 190 & 640 & 130 & 750 & 0.01 & 0.04 & 0.01 & 0.03 \\
\hline 6 & 170 & 710 & 240 & 850 & 0.01 & 0.10 & 0.03 & 0.05 \\
\hline Metformin & 247 & 810 & 220 & 960 & 0.01 & 0.02 & 0.01 & 0.01 \\
\hline Phenformin & 160 & 720 & 240 & 890 & 0.02 & 0.12 & 0.04 & 0.07 \\
\hline
\end{tabular}

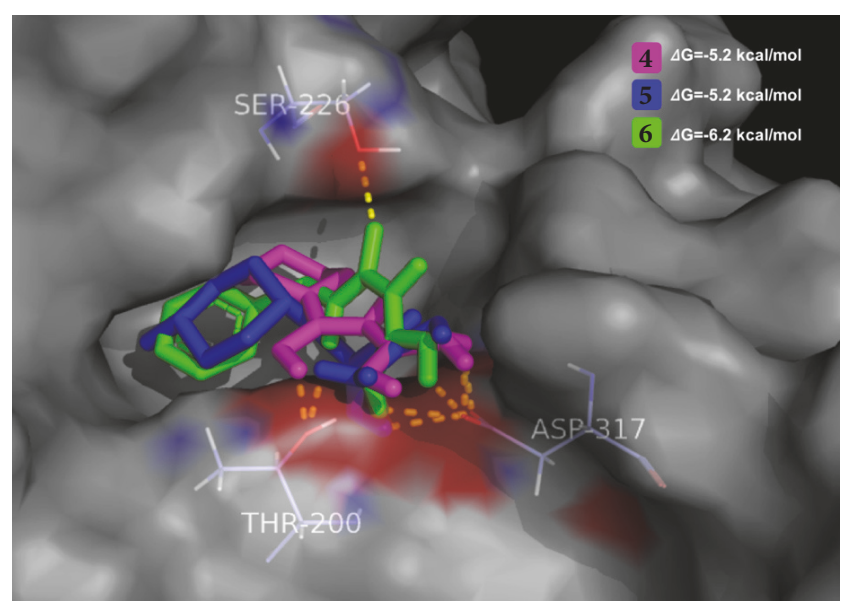

FIGURE 4: 3D binding model of compounds 4-6 into the nucleotide binding site of AMPK ( $\gamma$ subunit). Compounds 4 (cyan), 5 (blue), and 6 (green) are shown as stick models, whereas aminoacids are depicted as lines. A yellow dashed lines represent polar or electrostatic interactions.

additional interaction with Ser-226, increasing the docking energy to $-6.2 \mathrm{kcal} / \mathrm{mol}$. Figure 4 shows the binding mode of compounds 4-6 found by AutoDock showing an extensive hydrogen bonds network.

These results contribute to explaining at the molecular level the relevant activities of compounds 4-6 in the in vitro test.

3.3.2. In Silico Toxicity. With the aim of anticipating potential toxicity issues of compounds 4-6, a computational prediction of safety profiles was performed. The toxicity parameters of 4-6, metformin, and phenformin were calculated through the ACD/ToxSuite software, v. 2.95 (Table 2).

The in silico calculation of inhibition for the three main isoforms of CYP450 for compounds 4-6 was comparable to that of metformin at relevant clinical concentrations $(<10 \mu \mathrm{M})$, showing low probabilities of drug-drug interactions and undesirable adverse effects [17]. Several basic nitrogen compounds are associated with cardiovascular risks due to human ether-a-go-go related gene (hERG) channel blockade [18-20]. Compounds 4-6 showed low prediction of

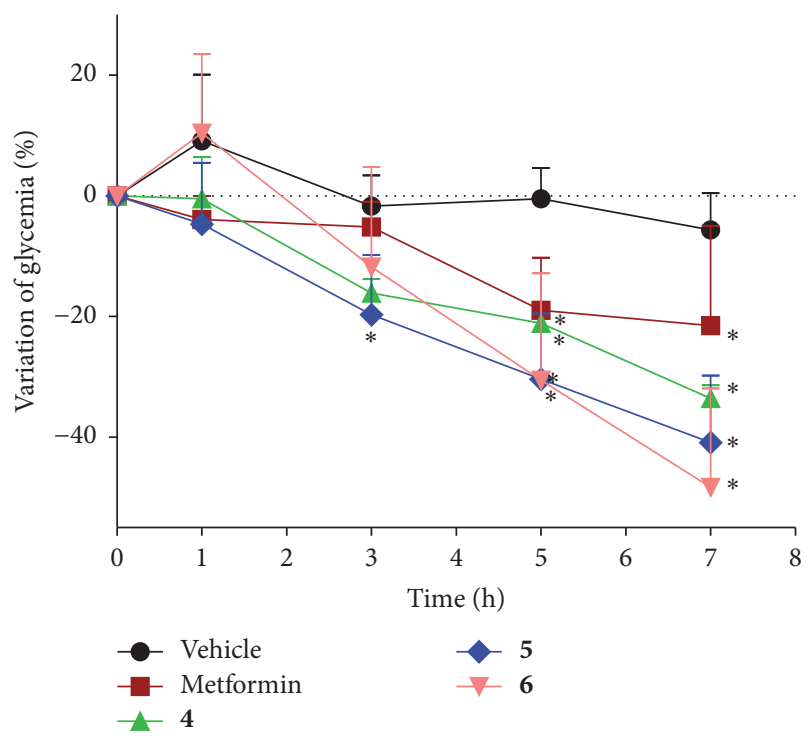

Figure 5: Effect of a single dose of compounds 4-6 and metformin $(50 \mathrm{mg} / \mathrm{Kg}$, intragastric, $n=5)$, or vehicle in streptozotocinnicotinamide-induced diabetes rat model. ${ }^{*} p<0.001$ versus vehicle group.

hERG channel blockage at clinically relevant concentrations $\left(K_{i}<10 \mu \mathrm{M}\right)$, being considered as potentially noncardiotoxic compounds. In the calculation of acute toxicity, compounds 4-6 demonstrated similar predicted $\mathrm{LD}_{50}$ than metformin and phenformin by two different administration routes.

3.4. In Vivo Antidiabetic Effect of Compounds 4-6. Compounds 4-6 were the most potent AMPK activators of the series, and they were selected in order to evaluate their in vivo antidiabetic activity using an STZ-nicotinamide noninsulin-dependent diabetes mellitus rat model. Metformin $(50 \mathrm{mg} / \mathrm{kg})$ was used as a positive control. The antidiabetic activity of compounds 4-6 was determined using a $50 \mathrm{mg} / \mathrm{kg}$ single dose, by intragastric route (Figure 5).

The antidiabetic assay shows that analogue $\mathbf{4}$ significantly reduced glucose levels compared to the vehicle and is as good as to the control group (metformin), having at 7 hours after administration a percentage of glucose decrease of $33.5 \%$. Analogue 5 also decreased glucose levels compared to 


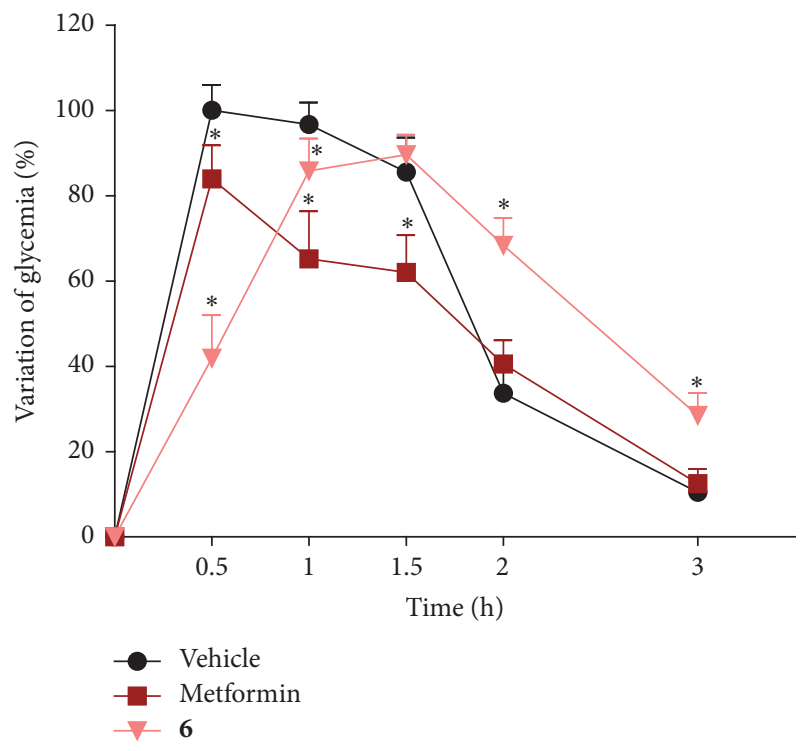

FIgURE 6: Oral glucose tolerance test. Effect of a single dose of compound 6 and metformin $(50 \mathrm{mg} / \mathrm{Kg}$, intragastric, $n=5)$, or vehicle in streptozotocin-nicotinamide-induced diabetes rat model. ${ }^{*} p<0.05$ versus vehicle.

vehicle. In addition, its effect was similar to that presented by metformin at the same dose. The activity was retained during the 7 hours of experimentation. At 7 hours after administration, a $40 \%$ decrease in blood glucose levels was observed. Analogue 6, which was the compound that showed the best activity on AMPK activation, was also active in the in vivo assay, and its antihyperglycemic effect was retained throughout the assay.

In order to verify the plausible antihyperglycemic effect of compound $\mathbf{6}$, glucose tolerance test curves in normoglycemic rats were obtained. Dose of $50 \mathrm{mg} / \mathrm{kg}$ for $\mathbf{6}$ and metformin was employed. As shown in Figure 6, compound $\mathbf{6}$ displayed a significant reduction of hyperglycemic peak which was attained at $0.5 \mathrm{~h}$ after glucose administration. In Figure 6, it can be seen that the animals treated with analogue 6 reached a lower hyperglycemic value than the animals treated with metformin and compared to the vehicle, $0.5 \mathrm{~h}$ after the treatment.

During the experiment, glucose levels did not decrease beyond baseline, indicating that the antidiabetic effect of compound $\mathbf{6}$ is due to an antihyperglycemic action rather than a hypoglycemic effect. Also, compounds 4-6 did not increase the lactic acid concentrations in plasma of rats tested (less than $1.9 \mathrm{mM}$ ), so any evidence of lactic acidosis was found. With these results, it can be concluded that the mechanism of action of the analogues 4-6 that confer their antidiabetic activity is similar to metformin, through the activation of AMPK and of some of the pathways that are regulated by this enzyme. Previously in vitro reports agree with the AMPK results obtained with compound 6 [15]. However, in our current study, we have demonstrated the robust in vivo effect produced by this compound after an oral administration. Further studies are being conducted by us in order to demonstrate the cardiovascular action of compound 6 in a murine model of fructose-induced insulin resistance [21].

\section{Conclusion}

In summary, ten alkarylbiguanides have been developed as promising compounds for the treatment of type 2 diabetes mellitus. Compounds 4-6 (a) exhibited AMPK activation similar to or greater than metformin, (b) demonstrated a robust reduction of glucose levels with marked in vivo antihyperglycemic efficacy, and (c) showed predicted low toxicity profiles and any experimental evidence of lactic acidosis. These compounds could be an alternative to metformin, the only biguanide currently available.

\section{Disclosure}

The paper is taken in part from the M. Pharm. thesis of E. Gutierrez-Lara.

\section{Conflicts of Interest}

The authors declare that there are no conflicts of interest regarding the publication of this paper.

\section{Acknowledgments}

This work was supported in part by the Consejo Nacional de Ciencia y Tecnología (CONACyT) under Grant no. 253814 (CB-2015). The authors are in debt with Abraham GutierrezHernandez, M. Pharm. for technical assistance. This article is dedicated to all the people, mainly Pharmacist, who helped in the medication management and classification after the recent Mexico's earthquake.

\section{References}

[1] American Diabetes Association, "Diagnosis and classification of diabetes mellitus," Diabetes Care, vol. 32, supplement 1, pp. S62-S67, 2009.

[2] S. Meng, J. Cao, Q. He et al., "Metformin activates AMPactivated protein kinase by promoting formation of the $\alpha \beta \gamma$ heterotrimeric complex," The Journal of Biological Chemistry, vol. 290, no. 6, pp. 3393-3802, 2015.

[3] E. Moreno-Arriola, M. El Hafidi, D. Ortega-Cuéllar, and K. Carvajal, "AMP-activated protein kinase regulates oxidative metabolism in Caenorhabditis elegans through the NHR-49 and MDT-15 transcriptional regulators," PLoS ONE, vol. 11, no. 1, Article ID 0148089, 2016.

[4] K. O. Cameron and R. G. Kurumbail, "Recent progress in the identification of adenosine monophosphate-activated protein kinase (AMPK) activators," Bioorganic \& Medicinal Chemistry Letters, vol. 26, no. 21, pp. 5139-5148, 2016.

[5] L. Yang, H. Sha, R. L. Davisson, and L. Qi, "Phenformin activates the unfolded protein response in an AMP-activated protein kinase (AMPK)-dependent manner," The Journal of Biological Chemistry, vol. 288, no. 19, pp. 13631-13638, 2013. 
[6] S. Hidalgo-Figueroa, J. J. Ramírez-Espinosa, S. Estrada-Soto et al., "Discovery of thiazolidine-2,4-dione/biphenylcarbonitrile hybrid as dual ppar $\alpha / \gamma$ modulator with antidiabetic effect: in vitro, in silico and in vivo approaches," Chemical Biology \& Drug Design, vol. 81, no. 4, pp. 474-483, 2013.

[7] S. Hidalgo-Figueroa, G. Navarrete-Vázquez, S. Estrada-Soto et al., "Discovery of new dual PPAR $\gamma$-GPR40 agonists with robust antidiabetic activity: Design, synthesis and in combo drug evaluation," Biomedicine \& Pharmacotherapy, vol. 90, pp. 53-61, 2017.

[8] M. N. Berry and D. S. Friend, "High-yield preparation of isolated rat liver parenchymal cells: a biochemical and fine structural study.," The Journal of Cell Biology, vol. 43, no. 3, pp. 506-520, 1969.

[9] U. Albus, "Guide for the Care and Use of Laboratory Animals (8th edn)by the National Research Council of the NationalAcademiesWashington, DC: National Academies Press, 2011," Laboratory Animals, vol. 46, no. 3, pp. 267-268, 2012.

[10] J. A. García-Díaz, G. Navarrete-Vázquez, S. García-Jiménez et al., "Antidiabetic, antihyperlipidemic and anti-inflammatory effects of tilianin in streptozotocin-nicotinamide diabetic rats," Biomedicine \& Pharmacotherapy, vol. 83, pp. 667-675, 2016.

[11] E. J. Verspohl, "Recommended testing in diabetes research," Planta Medica, vol. 68, no. 7, pp. 581-590, 2002.

[12] S. N. Goyal, N. M. Reddy, K. R. Patil et al., "Challenges and issues with streptozotocin-induced diabetes-a clinically relevant animal model to understand the diabetes pathogenesis and evaluate therapeutics," Chemico-Biological Interactions, vol. 244, pp. 49-63, 2016.

[13] R. R. Ortiz-Andrade, J. C. Sánchez-Salgado, G. NavarreteVázquez et al., "Antidiabetic and toxicological evaluations of naringenin in normoglycaemic and NIDDM rat models and its implications on extra-pancreatic glucose regulation," Diabetes, Obesity \& Metabolism, vol. 10, no. 11, pp. 1097-1104, 2008.

[14] R. B. Silverman and M. W. Holladay, The organic chemistry of drug design and drug action, Academic Press, San Diego, Calif, USA, 3rd edition, 2014.

[15] H. R. Bridges, V. A. Sirviö, A.-N. A. Agip, and J. Hirst, "Molecular features of biguanides required for targeting of mitochondrial respiratory complex I and activation of AMPkinase," BMC Biology, vol. 14, no. 1, article 65, 2016.

[16] O. Scudiero, E. Nigro, M. L. Monaco et al., "New synthetic AICAR derivatives with enhanced AMPK and ACC activation," Journal of Enzyme Inhibition and Medicinal Chemistry, vol. 31, no. 5, pp. 748-753, 2016.

[17] L. Xu, Y. Chen, Y. Pan, G. L. Skiles, and M. Shou, "Prediction of human drug-drug interactions from time-dependent inactivation of CYP3A4 in primary hepatocytes using a populationbased simulator," Drug Metabolism and Disposition, vol. 37, no. 12, pp. 2330-2339, 2009.

[18] O. Taboureau and F. S. Jørgensen, "In silico predictions of hERG channel blockers in drug discovery: from ligand-based and target-based approaches to systems chemical biology," Combinatorial Chemistry \& High Throughput Screening, vol. 14, no. 5, pp. 375-387, 2011.

[19] G. Navarrete-Vázquez, H. Torres-Gómez, S. Hidalgo-Figueroa et al., "Synthesis, in vitro and in silico studies of a PPAR $\gamma$ and GLUT-4 modulator with hypoglycemic effect," Bioorganic \& Medicinal Chemistry Letters, vol. 24, no. 18, pp. 4575-4579, 2014.

[20] G. Navarrete-Vázquez, A. Austrich-Olivares, B. GodínezChaparro et al., "Discovery of 2-(3,4-dichlorophenoxy)-N-(2morpholin-4-ylethyl)acetamide: A selective $\sigma 1$ receptor ligand with antinociceptive effect," Biomedicine \& Pharmacotherapy, vol. 79, pp. 284-293, 2016.

[21] E. J. Gutiérrez-Lara, G. Navarrete-Vázquez, A. Sánchez-López, and D. Centurión, "Pharmacological evaluation of metformin and $\mathrm{N}$ - benzylbiguanide, a novel analogue of metformin, on the vasopressor responses to adrenergic system stimulation in pithed rats with fructose-induced insulin resistance," European Journal of Pharmacology, vol. 814, pp. 313-323, 2017. 

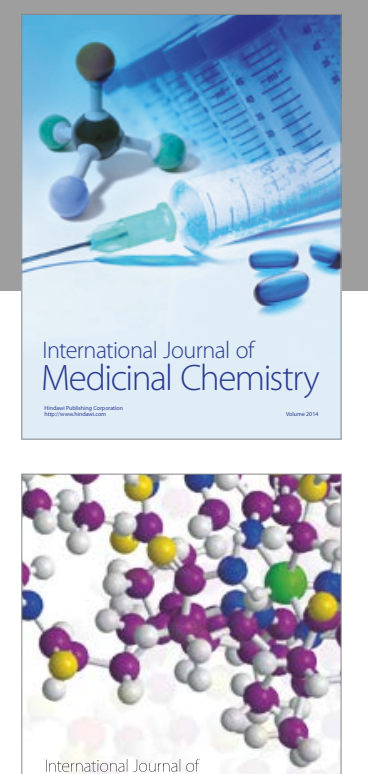

Carbohydrate Chemistry

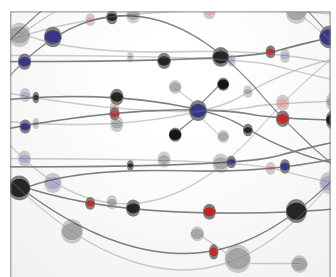

The Scientific World Journal
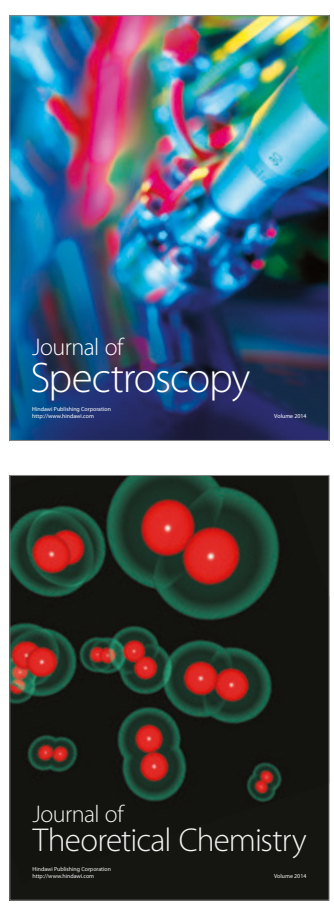
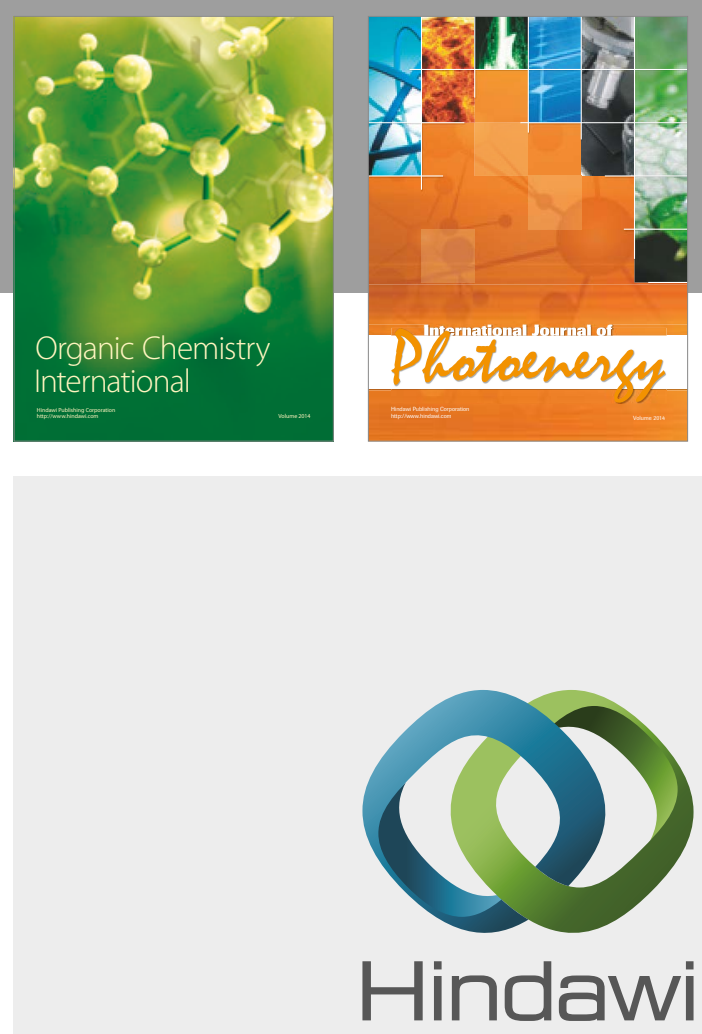

Submit your manuscripts at

https://www.hindawi.com

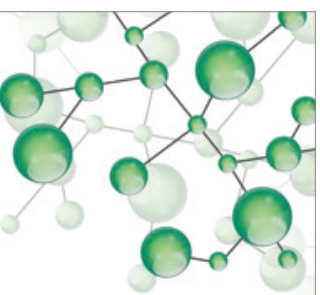

International Journal of

Inorganic Chemistry

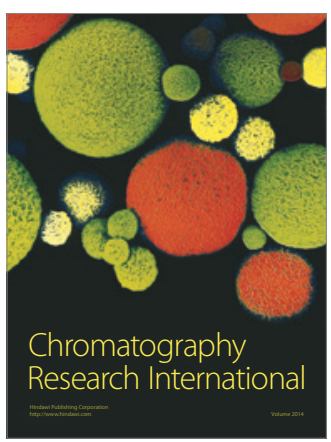

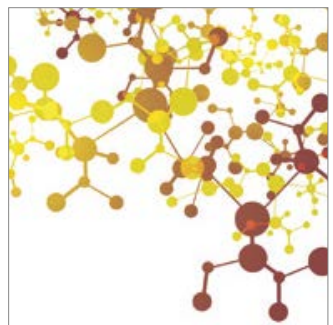

Applied Chemistry
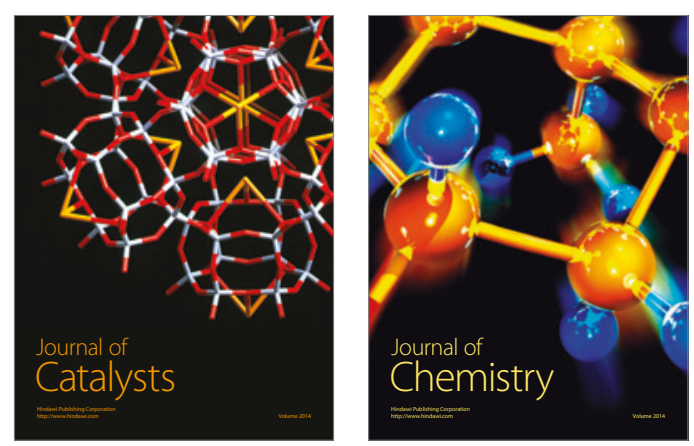
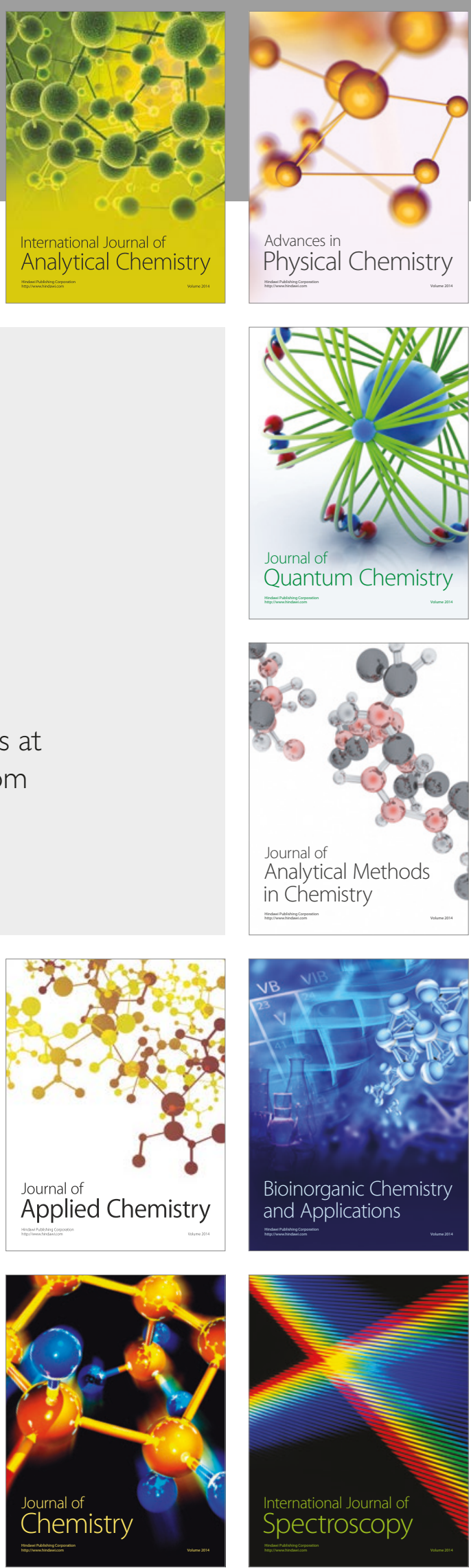